\title{
The Effect of Progestogen-Only Contraceptive Methods on Female Sexual Function in First-Time Users: A Cross- Sectional Study
}

\author{
Mohammed K Ali, Ali Shouman, Mohammed Khalaf, Ahmed M Abbas* and Ahmed Makhlouf
}

Department of Obstetrics and Gynecology, Faculty of Medicine, Assiut University, Assiut, Egypt

\begin{abstract}
Objective: To assess the female sexual function (FSF) in three progestogen-only contraceptives (POC) methods in firsttime users.

Methods: A cross-sectional study was conducted between May 2017 and February 2019 at the contraception clinic of a tertiary care hospital. Sexually active women aged between 20 and 40 years who have used POCs for at least six months were considered eligible. Similar numbers of women who have never used contraception were included as a control group (group I). Eligible women were divided according to the POC method to depot medroxyprogesterone acetate (DMPA) injection users (group II), sub dermal implants (group III), and desogestrel pill users (group IV). All women were surveyed for the prevalence of female sexual dysfunction (FSD) using the Arabic version of the female sexual function index (ArFSFI). (Clinicaltrial.gov:NCT02579590).
\end{abstract}

Results: Two hundred twenty-two women were included; 88 women were using DMPA, 87 women were using implants, and 47 women were on pills. The prevalence of FSD among POC users was significantly higher compared to the control group (57.6\% vs. $47.2 \%$, respectively, $\mathrm{P}=0.02$ ). Comparing POC users, DMPA users had lower mean ArFSFI scores than implant or pill users $(25.46 \pm 1.75,26.13 \pm 1.89,27.37 \pm 1.93$, respectively, $\mathrm{P}=0.01$; respectively). The relative risk of FSD among POC users was $1.21(95 \% \mathrm{Cl}=1.019-1.457)$.

Conclusions: Use of POC may be associated with a higher prevalence of FSD. Among POC users, women using DMPA may be more likely to experience FSD compared to women using pills or sub dermal implants, suggesting a dose-related effect.

\section{Keywords}

Contraception, Female sexual dysfunction, Progestogen-only contraceptive, ARFSFI

\section{Introduction}

Female sexuality is a vital element of human life and a complex function that involves several anatomical, hormonal, and psychological factors [1,2]. Female sexual dysfunction (FSD) is a prevalent problem, ranging from $30 \%$ to $63 \%$, which has a negative effect on men, women, and public health [3]. In Egypt, a high prevalence of FSD was previously reported reaching as high as $76.9 \%$ [4].

The female sexual function index (FSFI) is a common clinical tool used to assess FSD [5]. The ARFSFI was validated in the Egyptian population by Anis, et al., who concluded that the ArFSFI is a reliable and established tool for assessing FSD in the Arabic-speaking population [6].

The hormonal contraceptive methods contain sexual hormones (estrogens and progestogens); these hormones have a special effect on the central nervous system and vaginal tissues [7]. The use of progestogen-only contraceptive (POC) methods has been increased obviously and progressively over the world in the last few years [8]. These methods rely on progestogen alone to achieve contraception like progestogen-only pills, sub-dermal implants, DMPA injection, and levonorgestrel intrauterine system [9].

*Corresponding author: Ahmed M Abbas, Department of Obstetrics and Gynecology, Faculty of Medicine, Assiut University, Women Health Hospital, Assiut, 71511, Egypt, Tel: +20882414616; +20-10033851833, Fax: +20889202503

Accepted: November 18, 2020

Published online: November 20, 2020

Citation: Ali MK, Shouman A, Khalaf M, et al. (2020) The Effect of Progestogen-Only Contraceptive Methods on Female Sexual Function in First-Time Users: A Cross-Sectional Study. Annals Gynecol Obstet 4(2):97-104 
Citation: Ali MK, Shouman A, Khalaf M, et al. (2020) The Effect of Progestogen-Only Contraceptive Methods on Female Sexual Function in First-Time Users: A Cross-Sectional Study. Annals Gynecol Obstet 4(2):97-104

Many studies in the literature reported the negative Impact of estrogen-containing contraceptive methods on female sexual function (FSF) due to a decrease in the bioavailability of testosterone as well as an increased level of sex hormone-binding globulin (SHBG), which finally leads to a decline in free testosterone level contributes to $\operatorname{FSD}[10,11]$. However, POC methods contain no estrogen, so it has less effect on SHBG and, therefore, less effect on free testosterone level [12]. Despite the widespread use of POC methods, its effect on female sexuality is unclear. Limited studies have been conducted to evaluate women's sexual function using POC methods $[13,14]$.

Therefore, the current study evaluates the FSF among three different POC methods (DMPA, etonogestrel implant, and desogestrel-containing pills) for first-time users only.

\section{Patients and Methods}

The study was a single-center, cross-sectional, registered study (clinicaltrial.gov:NCT02579590). The institutional ethical review board approved the study. The women were recruited from The Family Planning Clinic of a tertiary University Hospital between May 2017 and February 2019. Women who met the selection criteria of the study were invited to participate after signing informed consent.

\section{Eligible participants}

We included married Egyptian women aged between 20-40 years with a heterosexually active relationship lasting longer than four weeks. They were using DMPA, etonogestrel implant, and desogestrel-containing pills for at least six months for contraception only. Those women were first-time users with a regular menstrual pattern, amenorrhea, or minimal vaginal spotting, not affecting sexual life. Lastly, all women were able to give consent and able to read and understand Arabic.

On the other hand, we excluded women who had any contraindication to the POC methods [15]. Women were also excluded if they had chronic pelvic pain [16], severe menstrual disturbance (known as bleeding free interval less than 15 days in the last months), or abstinence from sexual intercourse was required. Exclusion criteria also included women with a sexual aversion, phobic disorder or sexual pain disorder or use of antidepressants, antipsychotic drugs, or hormonal treatment in the last three months. Lastly, women with chronic or severe medical illnesses, psychiatric problems, or refused participation in the study were excluded.

\section{Enrollment}

The study included four groups of women. Group I (non-contraceptive users) consisted of women with no contraception use (either using natural methods or desiring pregnancy) between 20-40 years with regular cycles and no medical disorders. Group II (the DMPA users) were using Depot Medroxyprogesterone Acetate 150 mg (DMPA; Pharmacia, Nasr City, Cairo, Egypt) injection every three months while group III were using etonogestrel $68 \mathrm{mg}$ implant (Implanon; Merck Sharp \& Dohme Corp., Whitehouse Station, NJ 08889, USA). Group IV was using desogestrel 75 micrograms (Cera- zette; Merck Sharp \& Dohme Corp., Whitehouse Station, NJ 08889, USA); one pill every day for 28 days without pill-free interval.

After signing the consent, each woman was taken to a private room for obtaining the socio-demographic data (age, ethnicity, education, occupation, religion, marital status, and obstetric-gynecological data). History of circumcision was obtained. As regard contraceptive users, the type of contraception and the duration of its use were also recorded. All patients were subjected to a general examination followed by abdominal and pelvic examination. During a pelvic exam, the genital organs were examined well to confirm the absence or presence of genital mutilation and state its type and exclude causes of local dyspareunia and report the uterine or adnexal tenderness if present.

Then all women were asked to complete the FSFI questionnaire by themselves or with a trained nurse if they needed it. The FSFI was translated into the Arabic language (ARFS$\mathrm{FI}$ ) in a simple formal Arabic to be clear and understandable [6]. The ArFSFI questionnaire includes six domains includes 19 questions, which give scores on six domains of sexual function (desire, arousal, lubrication, orgasm, satisfaction, and pain) as well as a total score. The participated women answered all questions in about 20 minutes. Each question was answered using a 5-point Likert scale, and scores were expressed finally by multiplying domain scores by a factor of 0.3-0.6 to equally weigh each domain according to the number of questions per domain (two questions evaluated desire and had 0.6 score for each, three questions evaluated orgasm, satisfaction, and pain and had 0.4 score for each, and four questions evaluated arousal and lubrication and had 0.3 score for each). The maximum score for each domain is 6 , and the maximum transformed total score is 36 [17]. A total score of less than or equal to 28.1 points was determined as FSD [6].

\section{Study outcomes}

The primary outcome was to identify the prevalence of FSD among three POC users (DMPA, etonogestrel implant, and desogestrel-containing pills) assessed by the ArFSFI. At the same time, the secondary outcome included the effect of these POC methods on FSD subtypes. Finally, we tried to find the potential clinical predictors associated with FSD among POC users.

\section{Sample size}

A previous survey of Egyptian women without contraception use described a prevalence of FSD is $62.2 \%$ using ArFSFI (A total score of 28.1 or less is clinically associated with sexual dysfunction) [6]. We assumed to display a difference of $13 \%$ in the total ArFSFI score between non-contraceptive and POC users; using a two-sided chi-square $\left(\chi^{2}\right)$ test with $\alpha$ of 0.05 , a total sample size of at least 444 patients ( 222 for non-contraceptive users and 222 for POC users) at $80 \%$ power (Epi-info ${ }^{\mathrm{TM}}, \mathrm{CDC}$, USA).

\section{Statistical analysis}

The data was collected and entered on Microsoft access database to be analyzed using the Statistical Package for So- 
Citation: Ali MK, Shouman A, Khalaf M, et al. (2020) The Effect of Progestogen-Only Contraceptive Methods on Female Sexual Function in First-Time Users: A Cross-Sectional Study. Annals Gynecol Obstet 4(2):97-104

cial Science (SPSS Inc., Chicago, version 21). Comparisons between the four groups were performed using the ANOVA test to compare the mean values in scale variables. Categorical data were shown by number or percentage. Subgroup analysis was calculated for comparing the sexual function in each factor by using the Pearson Chi-square test. To examine the association between patient's clinical characteristics and FSD among POC users, a multiple logistic regression model was utilized. We constructed receiver operating characteristic (ROC) curves to evaluate the sensitivity, specificity, positive predictive value, negative predictive value, the accuracy of the potential predictors revealed by logistic regression. The $p$-value $<0.05$ was considered statistically significant.

\section{Results}

Four hundred sixty women were counseled for participation; however, 16 women were excluded (not met the inclusion criteria). Four hundred forty-four women consented to participate and divided into two groups; 222 women were non-contraceptive users, and 222 women were POC users ( 88 women were DMPA users, 87 women were implant users, and 47 women were pills users).

All groups (non-contraceptive users and POC users) were homogenous in the baseline socio-demographic data with no statistically significant differences (Table 1). Most of the participants were delivered before by cesarean section $(50.67 \%)$,

Table 1: Demographic data of study participants.

\begin{tabular}{|c|c|c|c|c|c|}
\hline N (\%) & $\begin{array}{l}\text { Non-contraceptive users } \\
(\mathrm{n}=\mathbf{2 2 2})\end{array}$ & $\begin{array}{l}\text { DMPA } \\
(\mathrm{N}=\mathbf{8 8})\end{array}$ & $\begin{array}{l}\text { Etonogestrel implant } \\
(\mathrm{n}=\mathbf{8 7})\end{array}$ & $\begin{array}{l}\text { Desogestrel pills } \\
(n=47)\end{array}$ & P-Value \\
\hline \multicolumn{6}{|l|}{ Age (Years) } \\
\hline$<20$ & $18(8.1)$ & $5(5.7)$ & $6(6.9)$ & $6(12.8)$ & 0.787 \\
\hline $21-30$ & 93 (41.9) & $40(45.5)$ & $37(42.5)$ & $16(34.0)$ & \\
\hline $31-40$ & $111(50.0)$ & $43(48.9)$ & $44(50.6)$ & $25(53.2)$ & \\
\hline \multicolumn{6}{|l|}{ Residence } \\
\hline Rural & $81(36.5)$ & $32(36.4)$ & $34(39.1)$ & 15 (31.9) & 0.879 \\
\hline Urban & $141(63.5)$ & $56(63.6)$ & $53(60.9)$ & $32(68.1)$ & \\
\hline \multicolumn{6}{|l|}{ Education } \\
\hline Illiterate & $104(46.8)$ & $40(45.5)$ & $42(48.3)$ & $22(46.8)$ & 0.996 \\
\hline Basic Education & $60(27.0)$ & $25(28.4)$ & $23(26.4)$ & $11(23.4)$ & \\
\hline Secondary or more & $58(26.1)$ & $23(26.1)$ & $22(25.3)$ & $14(29.8)$ & \\
\hline Circumcision & $165(74.3)$ & $68(77.3)$ & $62(71.3)$ & $33(70.2)$ & 0.757 \\
\hline \multicolumn{6}{|l|}{ Husband age } \\
\hline$<40$ & $49(22.1)$ & $27(30.7)$ & $26(29.9)$ & 7 (14.9) & 0.069 \\
\hline $40-50$ & $68(30.6)$ & $26(29.5)$ & $32(36.8)$ & $22(46.8)$ & \\
\hline$>50$ & $105(47.3)$ & 35 (39.8) & $29(33.3)$ & $18(38.3)$ & \\
\hline \multicolumn{6}{|l|}{ BMI } \\
\hline$<25 \mathrm{~kg} / \mathrm{m}^{2}$ & $46(20.7)$ & $18(20.5)$ & $20(23.0)$ & $10(21.3)$ & 0.973 \\
\hline$\geq 25 \mathrm{~kg} / \mathrm{m}^{2}$ & $176(79.3)$ & 70 (79.5) & $67(77.0)$ & 37 (78.7) & \\
\hline \multicolumn{6}{|l|}{ Religion } \\
\hline Muslim & 173 (77.9) & 65 (73.9) & $63(72.4)$ & $40(85.1)$ & 0.342 \\
\hline Christian & $49(22.1)$ & $23(26.1)$ & $24(27.6)$ & 7 (14.9) & \\
\hline Employment & $143(64.4)$ & $58(65.9)$ & $55(63.2)$ & $32(68.1)$ & 0.945 \\
\hline \multicolumn{6}{|c|}{ Frequency of sexual intercourse } \\
\hline 1-2 times/week & $106(47.7)$ & $45(51.1)$ & $42(48.3)$ & 23 (48.9) & 0.647 \\
\hline 3-4 times/week & $72(32.4)$ & $32(36.4)$ & $30(34.5)$ & $19(40.4)$ & \\
\hline$>4$ times/week & $44(19.8)$ & $11(12.5)$ & $15(17.2)$ & $5(10.6)$ & \\
\hline \multicolumn{6}{|c|}{ Duration of marriage (Years) } \\
\hline$<10$ & $88(39.6)$ & $33(37.5)$ & $40(46.0)$ & $25(53.2)$ & \\
\hline$\geq 10$ & $134(60.4)$ & $55(62.5)$ & $47(54.0)$ & $22(46.8)$ & 0.239 \\
\hline
\end{tabular}

BMI: Body mass index, DMPA: Depot Medroxyprogesterone Acetate, N (\%) number and percentage; *statistical significance if $p$-value $<0.05$. 
Citation: Ali MK, Shouman A, Khalaf M, et al. (2020) The Effect of Progestogen-Only Contraceptive Methods on Female Sexual Function in First-Time Users: A Cross-Sectional Study. Annals Gynecol Obstet 4(2):97-104

Table 2: Obstetric data of study participants.

\begin{tabular}{|c|c|c|c|c|c|}
\hline N (\%) & $\begin{array}{l}\text { Non-contraceptive } \\
\text { users }(n=222)\end{array}$ & DMPA $(\mathrm{N}=88)$ & $\begin{array}{l}\text { Etonogestrel implant } \\
(\mathbf{n}=87)\end{array}$ & $\begin{array}{l}\text { Desogestrel pills } \\
(n=47)\end{array}$ & P-Value \\
\hline Previous abortion & $16(7.2)$ & $5(5.7)$ & $6(6.9)$ & $4(8.5)$ & 0.937 \\
\hline Lactation & $153(68.9)$ & $63(71.6)$ & $59(67.8)$ & $32(68.1)$ & 0.951 \\
\hline \multicolumn{6}{|l|}{ Number of living children } \\
\hline $1-2$ & $106(47.7)$ & $43(48.9)$ & $38(43.7)$ & $18(38.3)$ & \\
\hline 3 or more & $116(52.3)$ & $45(51.1)$ & $49(56.3)$ & $29(61.7)$ & 0.600 \\
\hline \multicolumn{6}{|l|}{ Parity } \\
\hline$\leq 3$ & $96(43.2)$ & $36(40.9)$ & $46(52.9)$ & $25(53.2)$ & \\
\hline$>3$ & $126(56.8)$ & $52(59.1)$ & $41(47.1)$ & $22(46.8)$ & 0.239 \\
\hline \multicolumn{6}{|l|}{ Mode of delivery } \\
\hline Cesarean section & $107(48.2)$ & $45(51.1)$ & $47(54.0)$ & $26(55.3)$ & \\
\hline Normal vaginal delivery & $54(24.3)$ & $29(33.0)$ & $24(27.6)$ & $15(31.9)$ & \\
\hline Vaginal delivery with episiotomy & $61(27.5)$ & $14(15.9)$ & $16(18.4)$ & $6(12.8)$ & 0.140 \\
\hline
\end{tabular}

DMPA: Depot Medroxyprogesterone Acetate; N (\%) number and percentage.

Table 3: Comparison of FSF between non-contraceptive users and POC users.

\begin{tabular}{|l|l|l|l|}
\hline Mean \pm SD & Non-contraceptive users $\mathbf{( n = 2 2 2 )}$ & POC users (n = 222) & P-Value \\
\hline Desire & $4.76 \pm 0.61$ & $4.05 \pm 1.18$ & $0.000^{*}$ \\
\hline (95\% Cl) & $(4.68 \pm 4.84)$ & $(3.89 \pm 4.20)$ & $0.024^{*}$ \\
\hline Arousal & $4.58 \pm 0.68$ & $4.44 \pm 0.68$ & 0.065 \\
\hline (95\% Cl) & $(4.49 \pm 4.67)$ & $(4.35 \pm 4.53)$ & \\
\hline Lubrication & $4.50 \pm 0.66$ & $4.63 \pm 0.75$ & 0.522 \\
\hline (95\% Cl) & $(4.42 \pm 4.59)$ & $(4.53 \pm 4.73)$ & \\
\hline Orgasm & $4.55 \pm 0.73$ & $4.59 \pm 0.78$ & 0.529 \\
\hline (95\% Cl) & $(4.45 \pm 4.64)$ & $(4.49 \pm 4.69)$ & \\
\hline Satisfaction & $4.56 \pm 0.67$ & $4.60 \pm 0.81$ & 0.077 \\
\hline (95\% Cl) & $(4.47 \pm 4.64)$ & $(4.49 \pm 4.71)$ & \\
\hline Pain & $4.48 \pm 0.69$ & $4.61 \pm 0.80$ & $0.001^{*}$ \\
\hline (95\% Cl) & $(4.39 \pm 4.57)$ & $(4.50 \pm 4.71)$ & \\
\hline Total ArFSFI score & $27.42 \pm 2.02$ & $24.92 \pm 1.88$ & $0.021^{*}$ \\
\hline (95\% Cl) & $(27.16 \pm 27.69)$ & $(24.67 \pm 27.16)$ & $128(57.6 \%)$ \\
\hline No. of women with FSD & $105(47.2 \%)$ & & \\
\hline
\end{tabular}

ArFSFI: Arabic Female Sexual Function Index; Cl: Confidence Interval; FSF: Female Sexual Function; POC: Progesterone Only Contraception; SD: Standard Deviation; "Variable presented by number and percentage; ${ }^{*}$ Statistical significance if $\mathrm{p}$-value $<0.05$.

and about $70 \%$ were lactating (Table 2). No significant difference was observed between POC users as regards the duration of use $(p=0.795)$.

The comparison between FSF in non-contraceptive and POC users was shown in (Table 3). The mean ARFSFI score was significantly lower in POC users than non-contraceptive users ( $24.92 \pm 1.88$ vs. $27.42 \pm 2.02, p=0.006$; respectively). Also, the number of women with FSD was significantly higher in POC versus non-contraceptive users [128 (57.6\%) vs. 105 (47.2\%) women, $p=0.021$; respectively]. Dealing with each of the ARFSFI domains, desire and arousal scores were significantly lower in POC users ( $p=0.000$ and 0.024 , respectively). There were no statistically significant differences in the oth- er domains in both groups (Table 3). The relative risk of FSD among POC users was $1.21(95 \% \mathrm{Cl}=1.019-1.457)$.

Table 4 showed that the mean ArFSFI score was significantly lower in DMPA users in comparison to etonogestrel implant and desogestrel pills users $(25.46 \pm 1.75,26.13 \pm$ $1.89,26.37 \pm 1.93, p=0.010$; respectively). Furthermore, the number of women with FSD was significantly higher in DMPA users in comparison to other users [68 women (77.2\%), 44 women (50.5\%), 16 women (34.0\%), $p=0.000$; respectively]. The desire and lubrication scores were significantly lower in DMPA users ( $p=0.000$ and 0.009 , respectively).

The principal baseline characteristics that were revealed 
Citation: Ali MK, Shouman A, Khalaf M, et al. (2020) The Effect of Progestogen-Only Contraceptive Methods on Female Sexual Function in First-Time Users: A Cross-Sectional Study. Annals Gynecol Obstet 4(2):97-104

Table 4: Comparison of FSF between POC users.

\begin{tabular}{|c|c|c|c|c|}
\hline Mean \pm SD & DMPA $(n=88)$ & Etonogestrel implant $(n=87)$ & Desogestrel pills $(n=47)$ & P-Value \\
\hline Desire & $3.18 \pm 1.27$ & $4.48 \pm 0.62$ & $4.88 \pm 0.63$ & $0.000^{*}$ \\
\hline$(95 \% \mathrm{Cl})$ & $(2.91 \pm 3.45)$ & $(4.35 \pm 4.61)$ & $(4.69 \pm 5.06)$ & \\
\hline Arousal & $4.51 \pm 0.68$ & $4.40 \pm 0.65$ & $4.37 \pm 0.73$ & 0.390 \\
\hline$(95 \% \mathrm{Cl})$ & $(4.37 \pm 4.66)$ & $(4.26 \pm 4.54)$ & $(4.15 \pm 4.58)$ & \\
\hline Lubrication & $3.62 \pm 0.80$ & $4.62 \pm 0.72$ & $4.65 \pm 0.73$ & $0.009^{*}$ \\
\hline$(95 \% \mathrm{Cl})$ & $(3.45 \pm 3.70)$ & $(4.47 \pm 4.77)$ & $(4.43 \pm 4.86)$ & \\
\hline Orgasm & $4.49 \pm 0.79$ & $4.69 \pm 0.72$ & $4.60 \pm 0.84$ & 0.249 \\
\hline$(95 \% \mathrm{Cl})$ & $(4.33 \pm 4.66)$ & $(4.54 \pm 4.84)$ & $(4.35 \pm 4.84)$ & \\
\hline Satisfaction & $4.50 \pm 0.87$ & $4.47 \pm 0.70$ & $4.42 \pm 0.80$ & 0.313 \\
\hline$(95 \% \mathrm{Cl})$ & $(4.45 \pm 4.70)$ & $(4.32 \pm 4.62)$ & $(4.18 \pm 4.65)$ & \\
\hline Pain & $4.51 \pm 0.80$ & $4.47 \pm 0.77$ & $4.47 \pm 0.78$ & 0.327 \\
\hline$(95 \% \mathrm{Cl})$ & $(4.40 \pm 4.98)$ & $(4.30 \pm 4.63)$ & $(4.24 \pm 4.70)$ & \\
\hline Total ArFSFI score & $25.46 \pm 1.75$ & $26.13 \pm 1.89$ & $26.37 \pm 1.93$ & $0.010^{*}$ \\
\hline$(95 \% \mathrm{Cl})$ & $(25.09 \pm 25.83)$ & $(25.73 \pm 26.53)$ & $(25.80 \pm 26.94)$ & \\
\hline No. of women with FSD" & 68 (77.2\%) & $44(50.5 \%)$ & 16 (34.0\%) & $0.000^{*}$ \\
\hline
\end{tabular}

ArFSFI: Arabic Female Sexual Function Index; Cl: Confidence Interval; FSF: Female Sexual Function; POC: Progesterone Only Contraception; SD: Standard Deviation; "Variable presented by number and percentage; "Statistical significance if $p$-value $<0.05$.

Table 5: Multiple logistic regression analysis for the risk factors of FSD in POC users.

\begin{tabular}{|l|l|l|l|l|}
\hline & P-Value & OR & 95\% C.I. & Upper \\
\hline Age: (years) & & & & \\
\hline $40-50$ & 0.219 & & 0.079 & 1.265 \\
\hline$>50$ & 0.103 & 0.316 & 0.093 & 2.667 \\
\hline Circumcision & 0.415 & 0.497 & 1.768 & 8.517 \\
\hline Husband age (years) & $0.001^{*}$ & 3.880 & & 1.890 \\
\hline $40-50$ & 0.185 & & 0.282 & 5.663 \\
\hline$>50$ & 0.516 & 0.730 & 0.584 & \\
\hline Frequency of sexual intercourse & 0.302 & 1.819 & & 7.362 \\
\hline $1-2$ time/week & 0.141 & & 0.873 & 3.286 \\
\hline 3-4 times/week & 0.087 & 2.535 & 0.448 & 2.154 \\
\hline Duration of marriage $>$ 10 years & 0.703 & 1.214 & 0.261 & 5.785 \\
\hline Parity $>$ 3 times & 0.592 & 0.749 & 1.208 & 6.051 \\
\hline Duration of use of $>12$ months & $0.015^{*}$ & 2.644 & 1.151 & \\
\hline
\end{tabular}

POC: Progesterone Only Contraceptive; ${ }^{*}$ Statistical significance if $p$-value $<0.05$.

from the multiple regression model and significantly associated with a higher likelihood of FSD with POC were circumcision $(p=0.001)$, parity $>3$ times $(p=0.015)$, and duration of use $>$ 12 months $(p=0.022)$ (Table 5).

A ROC curve analysis in the predictive model demonstrated that circumcision yielded the highest sensitivity (82.84\%) while the parity $>3$ times had the lowest one (59.76\%), and the duration of use $>12$ months had a sensitivity of $60.36 \%$. However, when the three predictors were added together, the sensitivity was (34.32\%), specificity $(96.23 \%)$, positive predictive value $(96.7 \%)$, negative predictive value $(31.5 \%)$, and accuracy (49.10\%) (Table 6).

\section{Discussion}

Currently, there is limited evidence on the Impact of POC on female sexuality. Up to our knowledge, this is the first study compassing the prevalence of FSD among three common POC methods in Egypt. The effect of each POC method on FSD subtypes was also studied. Besides, we tried to explore the potential clinical predictors associated with FSD among those users. A high prevalence of FSD in POC users, particularly DMPA users, were observed in our study. The 
Citation: Ali MK, Shouman A, Khalaf M, et al. (2020) The Effect of Progestogen-Only Contraceptive Methods on Female Sexual Function in First-Time Users: A Cross-Sectional Study. Annals Gynecol Obstet 4(2):97-104

Table 6: Sensitivity, Specificity, +PV, -PV, accuracy and AUC of the potential predictors.

\begin{tabular}{|l|l|l|l|l|l|l|}
\hline Characteristic & Sensitivity & Specificity & +PV & -PV & Accuracy & AUC \\
\hline Circumcision & 82.84 & 56.60 & 85.9 & 50.8 & 76.58 & 0.697 \\
\hline Parity > 3 times & 59.76 & 73.58 & 87.8 & 36.4 & 63.06 & 0.667 \\
\hline Duration of use > 12 months & 60.36 & 69.81 & 86.4 & 35.6 & 62.61 & 0.651 \\
\hline Mixed risks & 34.32 & 96.23 & 96.7 & 31.5 & 49.10 & 0.653 \\
\hline
\end{tabular}

PV: Positive Predictive Value, -PV: Negative Predictive Value, AUC: Area Under the Curve.

desire, arousal, and lubrication scores were the domains affected. The circumcision, parity more than three times, and duration of use of more than 12 months were the significant clinical predictors of FSD among POC users.

Three important points should be discussed in our study. Firstly, we included only first-time users of POC methods; we think that previous use of these methods may negatively affect FSF. Secondly; the cutoff score of the ARFSFI questionnaire which distinguishes between women with or without sexual dysfunction is 28.1, as reported by Anis, et al. 2011 [6], not 26.55 (as the original FSFI) [18]; this cut off score was used for the first time in our study. Thirdly, we compared the FSF between three POC methods, which almost all have the same mechanism of action to increase our results' credibility. So, we did not include, in our study, the levonorgestrel minipills users (different mechanisms of action), levonorgestrel intrauterine system users (may increase sexual pain), or estrogen-containing methods.

Diagnosis of FSD among Arabic women (like Egyptian women) carries many challenges because of the conservative nature of those women making the communication quite difficult [19]. In Egypt, Elnashar, et al. 2007, in his study, reported that the prevalence of FSD was $68.9 \%$ in non-contraceptive users [20], while Hassanin, et al. 2010 reported a higher score of $76.9 \%$ [4]. The prevalence reported in their studies is higher than that reported in our study $(47.2 \%)$ because they used another toll of assessment of sexual function (not ArFSFI). However, Anis, et al. 2011 used the same questionnaire (ARFSFI) and reported a figure of (62.2\%) [6]. Collectively, the prevalence of FSD varies significantly because of different types of populations, age, habit, and lastly, other tools of assessment of FSF with different cutoff values [3].

The effect of contraception containing progestational agents on FSF is conflicting [21]. In our study, we found that the prevalence of FSD among POC users, 57.6\%. We also observed that DMPA was the most common method associated with FSD (77.2\%). The desire and lubrication were the most affected domains. We agree with Matson, et al. 1997, Paul, et al. 1997 and Hassanin, et al. 2018, who found that the use of DMPA was associated with decreased sexual desire $[13,22,23]$. However, Ott, et al. 2005, Schaffir, et al. 2010 and Ozgoli, et al. 2015 reported no detrimental effect of DMPA on FSF $[24,25]$. However, they compared, in their studies, DMPA with other methods containing estrogen.

The second affected domain with DMPA use was the lubrication. The hypo estrogenic state and thinning of the glycogen vaginal epithelial layer may be behind this effect [26].
Little information is present in literature regarding the Impact of the etonogestrel implant on FSF. In contrast to DMPA users, etonogestrel implant users may improve their sexual function $[27,28]$. But catastrophic anorgasmia may be complicated this implant after only three months of use [29]. In our study, $50.5 \%$ of etonogestrel implant users suffering from sexual dysfunction. Gezginc, et al. in 2007 told that only $2.5 \%$ of women had the implant removed due to decreased libido, but he did not mention the tool used to assess FSF in his study [30].

Regarding the desogestrel containing pills, we found that FSD was present in $34.0 \%$ of the users. The association between the FSD and progesterone-only pills (POPs) is very scarce in the literature. Some studies showing a positive effect on FSF, especially androgenic progestins (like levonorgestrel), and some of them reported a negative effect, especially newer-generation of progestins (like desogestrel and etonorgestrel) [29,31]. An old study by Graham, et al. 1995 reported that POPs did not exhibit any change in sexual desire or activity [32].

Our results emphasized that circumcision was a significant predictor of sexual dysfunction among POC users ( $p=0.001)$. Despite declining in the female circumcision rate in Egypt in the last decades [33], there are a significant number of circumcised women in our study (73.8\%). There is no doubt that circumcision affects the FSF negatively with or without POC use [34]. Another significant risk factor revealed from our study was the duration of use of more than 12 months. It is explainable because of its effect on suppressing or preventing $\mathrm{LH}$ and $\mathrm{FSH}$ release, resulting in decreased levels of estrogen and free testosterone [24]. The last one was parity more than three times. In this study, about $50 \%$ of the participants were delivered before vaginally. This risk factor could be understandable due to anatomical alternation in the pelvic floor muscle and different degrees of genital tract descent [20].

In the predictive model; circumcision showed the highest sensitivity $(82.84 \%)$, followed by the duration of use > 12 months $(60.36 \%)$ and finally the parity more than three times (59.76\%). However, when these risk factors were added together, much less sensitivity was getting (34.32\%), but the highest specificity appeared (96.23\%). These results are important to clinicians when counseling women who request POC methods.

This study has both strengths and weaknesses. A major strength of this study was its idea in comparing three POC methods together with the same mechanism; this is a new issue. Additionally, we included first-time users only because 
Citation: Ali MK, Shouman A, Khalaf M, et al. (2020) The Effect of Progestogen-Only Contraceptive Methods on Female Sexual Function in First-Time Users: A Cross-Sectional Study. Annals Gynecol Obstet 4(2):97-104

we think that the previous contraceptive users may experience sexual side effects. We added a control group (non-contraceptive users), which missed in many studies in the literature. Finally, we were able to recruit our calculated sample size for achieving sufficient power to detect a clinically significant difference according to our primary outcome.

However, the present work had some limitations. Inability to randomize each participant to a special contraceptive group making a significant difference between the numbers of women in each group. A major limitation in our study was the inability to assess the sexual function in our cohort before starting the contraceptive methods. This is because of the nature of our research, which included women using POCs for at least six months before recruitment. Our predictive model found only three significant predictors between our groups; this is because of the too-small sample for this model. Another issue is the absence of correlation between FSD and different levels of sexual hormones in each group. But it is not necessarily because the FSD may not related to hormonal changes influenced by the use of contraception. Finally, the small sample size that was available for the final analysis at the end of the study (222 women in each group).

\section{Conclusion}

The current results suggest that POC methods may be associated with a higher prevalence among first-time users compared to non-users, particularly among DMPA users. FSD was primarily attributed to decreased sexual desire, arousal, and lubrication. Counseling on current information may be necessary before initiation of DMPA, especially in women at higher risk of FSD. However, prospective studies and randomized controlled trials are recommended to facilitate understanding of these side effects.

\section{Conflict of Interest}

The authors declare that they have no conflict of interest.

\section{References}

1. Gracia CR, Sammel MD, Charlesworth S, et al. (2010) Sexual function in first-time contraceptive ring and contraceptive patch users. Fertil Steril 93: 21-28.

2. Alp Yilmaz F, Avci D, Arzu Aba Y, et al. (2018) Sexual dysfunction in postpartum Turkish women: Its relationship with depression and some risk factors. Afr J Reprod Health 22: 54-63.

3. Wallwiener CW, Wallwiener LM, Seeger H, et al. (2010) Prevalence of sexual dysfunction and impact of contraception in female German medical students. J Sex Med 7: 2139-2148.

4. Hassanin IM, Helmy YA, Fathalla MM, et al. (2010) Prevalence and characteristics of female sexual dysfunction in a sample of women from upper Egypt. Int J Gynaecol Obstetrics 108: 219223.

5. Isidori AM, Pozza C, Esposito K, et al. (2010) Development and validation of a 6 -item version of the female sexual function index (FSFI) as a diagnostic tool for female sexual dysfunction. J Sex Med 7: 1139-1146.

6. Anis TH, Gheit SA, Saied HS, et al. (2011) Arabic translation of female sexual function index and validation in an Egyptian population. J Sex Med 8: 3370-3378.
7. Shah M B, Hoffstetter S (2010) Contraception and sexuality. Minerva Ginecol 62: 331-347.

8. Vickery Z, Madden $T$, Zhao Q, et al. (2013) Weight change at 12 months in users of three progestin-only contraceptive methods. Contraception 88: 503-508.

9. Townsend JW, Sitruk-Ware R, Williams K, et al. (2011) New strategies for providing hormonal contraception in developing countries. Contraception 83: 405-409.

10. Panzer C, Wise S, Fantini G, et al. (2006) Impact of oral contraceptives on sex hormone-binding globulin and androgen levels: a retrospective study in women with sexual dysfunction. J Sex Med 3: 104-113.

11. Grimes DA, Schulz KF (2011) Nonspecific side effects of oral contraceptives: Nocebo or noise? Contraception 83: 5-9.

12. Burrows L, Basha M, Goldstein AT (2012) The effects of hormonal contraceptives on female sexuality: A review. J Sex Med 9: 2213-2223.

13. Hassanin AM, El-Halwagy AM, Ismail NN, et al. (2018) A study of the impact of the commonly used female contraceptive methods in Egypt on female sexual function. J Sex Marital Ther 44: 605-612.

14. Schaffir JA, Isley MM, Woodward M (2010) Oral contraceptives vs injectable progestin in their effect on sexual behavior. Am J Obstet Gynecol 203: 545.e1-e5.

15. Serfaty D (2019) Update on the contraceptive contraindications. J Gynecol Obstet Human Reprod 48: 297-307.

16. ACOG Committee on Practice Bulletins-Gynecology (2004) ACOG Practice Bulletin No. 51. Chronic pelvic pain. Obstet Gynecol 103:589-605.

17. Rosen R, Brown C, Heiman J, et al. (2000) The female sexual function index (FSFI): A multidimensional self-report instrument for the assessment of female sexual function. J Sex Marital Ther 26: 191-208.

18. Wiegel M, Meston C, Rosen R (2005) The female sexual function index (FSFI): Cross-validation and development of clinical cutoff scores. J Sex Marital Ther 31: 1-20.

19. Rahman S (2018) Female sexual dysfunction among muslim women: Increasing awareness to improve overall evaluation and treatment. Sex Med Rev 6: 535-547.

20. Elnashar AM, El-Dien Ibrahim M, El-Desoky MM, et al. (2007) Female sexual dysfunction in lower Egypt. BJOG 114: 201-206.

21. Casey PM, MacLaughlin KL, Faubion SS (2017) Impact of contraception on female sexual function. J Women's Health 26: 207213.

22. Matson SC, Henderson KA, McGrath GJ (1997) Physical findings and symptoms of depot medroxyprogesterone acetate use in adolescent females. J Ped Adolesc Gynecol 10: 18-23.

23. Paul C, Skegg DC, Williams S (1997) Depot medroxyprogesterone acetate. Patterns of use and reasons for discontinuation. Contraception 56: 209-214.

24. Ozgoli G, Sheikhan Z, Dolatian M, et al. (2015) Comparison of sexual dysfunction in women using depo-medroxyprogesterone acetate (DMPA) and Cyclofem. J Reprod Infertility 16: 102-108.

25. Ott MA, Shew ML, Ofner S, et al. (2008) The influence of hormonal contraception on mood and sexual interest among adolescents. Arch Sex Behav 37: 605-613. 
Citation: Ali MK, Shouman A, Khalaf M, et al. (2020) The Effect of Progestogen-Only Contraceptive Methods on Female Sexual Function in First-Time Users: A Cross-Sectional Study. Annals Gynecol Obstet 4(2):97-104

26. Miller L, Patton DL, Meier A, et al. (2000) Depomedroxyprogesterone-induced hypoestrogenism and changes in vaginal flora and epithelium. Obstetr Gynecol 96: 431-439.

27. Di Carlo C, Sansone A, De Rosa N, et al. (2014) Impact of an implantable steroid contraceptive (etonogestrel-releasing implant) on quality of life and sexual function: A preliminary study. Gynecol Endocrinol 30: 53-56.

28. Sansone A, De Rosa N, Giampaolino P, et al. (2018) Effects of etonogestrel implant on quality of life, sexual function, and pelvic pain in women suffering from endometriosis: Results from a multicenter, prospective, observational study. Arch Gynecol Obstet 298: 731-736.

29. Chapa HO, Ramirez A, Dawson D (2017) Etonogestrel contraceptive implant-associated secondary anorgasmia. Contraception 96: 254-256.
30. Gezginc K, Balci O, Karatayli R, et al. (2007) Contraceptive efficacy and side effects of Implanon. Eur J Contracept Reprod Health Care 12: 362-365.

31. Regidor PA (2018) The clinical relevance of progestogens in hormonal contraception: Present status and future developments. Oncotarget 9: 34628-34638.

32. Graham CA, Ramos R, Bancroft J, et al. (1995) The effects of steroidal contraceptives on the well-being and sexuality of women: $A$ double-blind, placebo-controlled, two-centre study of combined and progestogen-only methods. Contraception 52: 363-369.

33. Modrek S, Liu JX (2013) Exploration of pathways related to the decline in female circumcision in Egypt. BMC public health 13: 921.

34. Puri P, Kumar J, Ramesh V (2010) Circumcision. Ind J SexTransmit Dis AIDS 31: 69-74. 